Research Report

\title{
The benefits of retail therapy: Making purchase decisions reduces residual sadness
}

\author{
Scott I. Rick *, Beatriz Pereira, Katherine A. Burson \\ Ross School of Business, University of Michigan, 701 Tappan Street, Ann Arbor, MI 48109, USA
}

Received 14 August 2012; received in revised form 10 December 2013; accepted 22 December 2013

Available online 27 December 2013

\begin{abstract}
People often shop when feeling sad, but whether and why shopping reduces residual (lingering) sadness remains an open question. Sadness is strongly associated with a sense that situational forces control the outcomes in one's life, and thus we theorized that the choices inherent in shopping may restore personal control over one's environment and reduce residual sadness. Three experiments provided support for our hypothesis. Making shopping choices helped to alleviate sadness whether they were hypothetical (Experiment 1) or real (Experiment 2). In addition, all experiments found support for the underlying mechanism of personal control restoration. Notably, the benefits of restored personal control over one's environment do not generalize to anger (Experiments 2 and 3), because anger is associated with a sense that other people (rather than situational forces) are likely to cause negative outcomes, and these appraisals are not ameliorated by restoring personal control over one's environment.
\end{abstract}

(C) 2013 Society for Consumer Psychology. Published by Elsevier Inc. All rights reserved.

Keywords: Retail therapy; Shopping; Appraisal tendency theory; Sadness; Decision-making

\section{Introduction}

How do people regulate distress? Several common responses to distress have been documented, such as rumination, overeating, and alcohol consumption. Distress can also encourage unplanned purchases (e.g., Atalay \& Meloy, 2011, Study 1). Shopping that is motivated by distress-"retail therapy"-is often lamented as ineffective, wasteful, and a "dark side" of consumer behavior (Kasser \& Sheldon, 2000). Popular press accounts of retail therapy typically paint an equally dismal picture (Tuttle, 2010).

We propose that retail therapy has been viewed too negatively. Shopping may be an effective way to minimize sadness that lingers (residual sadness) following a sadness-inducing event. We focus on shopping's potential to reduce residual sadness in particular, as previous research has demonstrated that sadness increases comfort-seeking (Raghunathan, Pham, \& Corfman, 2006) and willingness-to-pay (Cryder, Lerner, Gross, \& Dahl, 2008; Lerner, Small, \& Loewenstein, 2004).

\footnotetext{
* Corresponding author.

E-mail addresses: srick@umich.edu (S.I. Rick), bpereira@umich.edu (B. Pereira), kburson@umich.edu (K.A. Burson).
}

Prior research has provided some suggestive evidence that shopping can convey psychological benefits (Gardner \& Rook, 1988). In a diary study, Atalay and Meloy (2011, Study 3) found that most participants reported positive feelings when reflecting on their most recent purchase that was motivated by a desire to repair mood. Faber and Christenson (1996, Table 3) found that people recalled that they were less likely to experience sadness while shopping than immediately before going shopping.

However, causal conclusions remain elusive, as no prior research investigating the influence of shopping on emotion or mood has utilized experimental designs. Without random assignment to shopping or equally engaging "control" activities, it is unclear whether shopping conveys benefits beyond those produced merely by distraction or the passage of time.

In addition, research in this area has only loosely conceptualized both affect and shopping. Atalay and Meloy (2011) utilized broad measures of mood (p. 642) and positive emotion and negative emotion indices (p. 653), rather than investigating the experience of specific emotions. Faber and Christenson (1996, p. 809) asked participants to report how they generally feel "while shopping," without referencing any specific shopping 
episode. Because "shopping" can have many components, including browsing, interacting with salespeople, choosing, paying, acquiring, and consuming, retrospective reports about "shopping" cannot shed light on which component(s) are necessary for healing to occur.

This last point is not merely a descriptive shortcoming. Differences in the effectiveness of specific components could shed light on why shopping reduces residual sadness. To develop hypotheses about why some components will be particularly influential, we consider sadness from an appraisal tendency theory perspective (Han, Lerner, \& Keltner, 2007). Appraisal theory suggests that the way people cognitively appraise their environment is both a cause and consequence of different emotions. Smith and Ellsworth (1985) identified six appraisals that differentiate emotions: the extent to which the current situation is pleasant, predictable, demanding of attention, demanding of effort, under human (versus situational) control, and under one's own or other people's control. Thus, similarly valenced emotions can differ on other important dimensions (e.g., anger and fear are both aversive, but anger is associated with greater certainty; Lerner \& Keltner, 2001).

Sadness, more than any other emotion, is associated with a perceived deficiency in personal control over one's environment (Smith \& Ellsworth, 1985). People who are sad are especially likely to view outcomes as governed by situational forces and chance, rather than their own actions. To the extent that these appraisals create or maintain the experience of sadness (Han et al., 2007), aspects of shopping that restore a sense of personal control over one's environment may subsequently reduce residual sadness. Indeed, Garg and Lerner (2013, p. 112) proposed that researchers should investigate whether "feeling less helpless correspond[s] with feeling less sad."

Prior research suggests that the ability to choose tends to enhance one's sense of personal control (Inesi, Botti, Dubois, Rucker, \& Galinsky, 2011; Langer, 1975). Because choices are inherent to shopping (e.g., choosing whether to buy), shopping may restore a sense of control and thus minimize residual sadness.

Of course, aside from choice, other aspects of the shopping experience could influence sadness. For example, shopping may provide distraction (cf. Kim \& Rucker, 2012) or social interaction (O'Guinn \& Faber, 1989). In what follows, we experimentally isolate the influence of choice on the experience of sadness by utilizing simplified paradigms that necessarily strip away extraneous factors that can accompany naturalistic shopping. For example, there is no consumption or social interaction in our experiments. We control for the benefits of distraction in Experiment 1 by including a "browsing" control condition, in which participants must interact with products but cannot buy any.

We focus on choice for two reasons. First, choice is the component of shopping that is most theoretically linked to personal control. Given that sadness is characterized by a lack of personal control over one's environment, the control imbued by making shopping choices may help reduce residual sadness. Second, we focus on choice because it is arguably the most fundamental component of shopping. While shopping may or may not involve factors not present in our experiments (e.g., social interaction), shopping always involves choice.

We propose that making shopping choices can help to restore a sense of personal control over one's environment, but many people may have difficulty quantifying and articulating the extent to which they feel control over their environment. (In their classic demonstration, Smith and Ellsworth (1985, p. 820) utilized a group of participants pre-screened to be highly emotionally expressive, and asked them to recall their experiences of control during a specific emotional event, rather than their current, ambient feelings of control over their environment.) Thus, in what follows we shed light on our proposed process by experimentally manipulating personal control (cf. Spencer, Zanna, \& Fong, 2005). We do so by manipulating whether participants can freely choose among a broad product assortment (Experiment 1), whether participants believe they can ensure that they obtain their preferred product (Experiment 2), and whether participants recall an instance of high or low control over their environment (Experiment 3).

\section{Experiment 1}

Experiment 1 tested the hypothesis that making shopping choices helps to restore personal control over one's environment, which can in turn help to alleviate residual sadness. We randomly assigned participants to choose which of several products they would hypothetically buy, or to judge which of those products would be most useful when traveling. Conceptually, our intention was to manipulate the extent to which participants could exercise personal autonomy during the task (since only a handful of the products are appropriate for travel, but any could be selected by hypothetical buyers), while holding constant distraction and (lack of) product acquisition across conditions.

\section{Method}

One hundred adults (52\% female, mean age: 36$)$ participated in an online study for a small payment. We recruited participants via Amazon Mechanical Turk (MTurk), a platform validated by Paolacci, Chandler, and Ipeirotis (2010). We initially collected a baseline measure of emotions. Specifically, participants indicated the extent to which they were currently experiencing seven different emotions (amused, sad, indifferent, angry, depressed, happy, rage), by moving a slider along a $12 \mathrm{~mm}$ line anchored by the labels "not at all" and "very much." Responses were scored on a $0-100$ scale based on where participants rested the slider.

Participants then viewed a three-minute clip from The Champ portraying the death of a boy's father, which reliably induces sadness (Rottenberg, Ray, \& Gross, 2007). We then took a second measure of emotions, identical to our baseline measure.

We then randomly assigned participants to a Choosing or Browsing condition, adapting a design by Mazar and Zhong (2010). Choosers were told to "imagine buying $\$ 100$ worth of products, by placing them in a shopping cart." Choosers then viewed 12 products (e.g., slippers, headphones; see Fig. 1), each priced at $\$ 25$. Choosers were asked to select four products 
Merkury Headphones

$\$ 25$

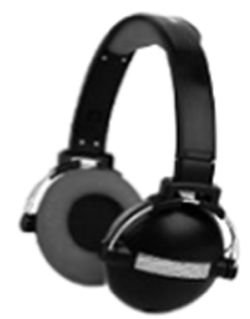

Wine Decanter $\$ 25$

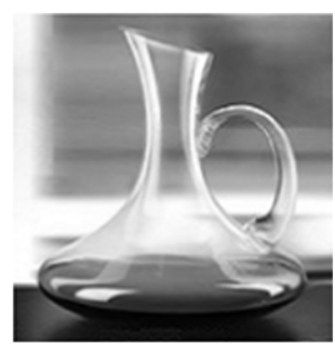

Marble Cheese Board $\$ 25$

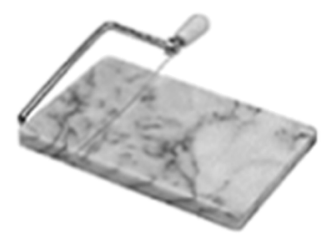

Salt and Pepper Grinder Set $\$ 25$

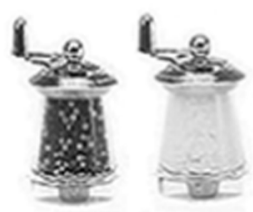

Gel Mask

$\$ 25$

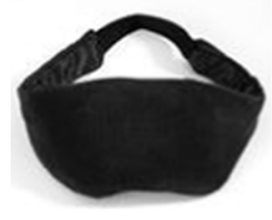

Homedics Massager $\$ 25$

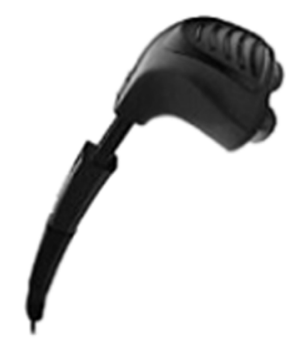

Memory Foam Slippers $\$ 25$

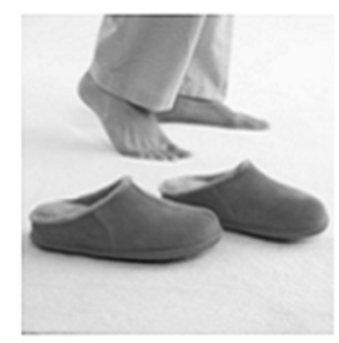

Flexible Wireless Keyboard $\$ 25$

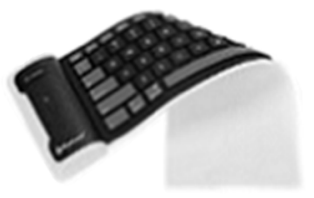

Apples to Apples

$\$ 25$

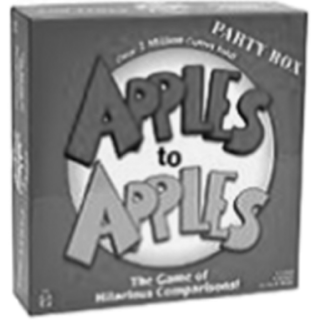

Wooden Puzzle

$\$ 25$

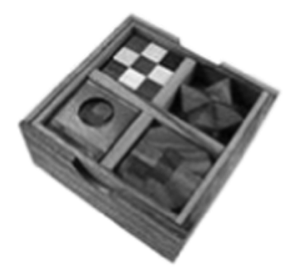

Pet Disc Lounge

$\$ 25$

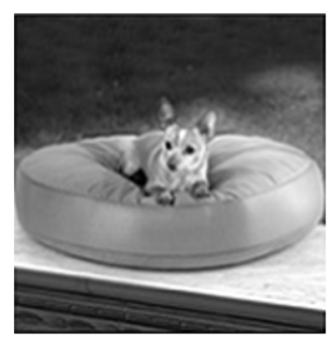

iHome Mini Speakers

$\$ 25$

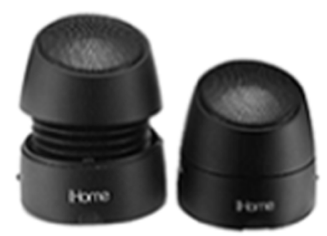

Fig. 1. Products utilized in Experiment 1.

they would hypothetically like to buy, by clicking on four products and dragging them into a box labeled "Your Shopping Cart." Choosers were informed that the shopping was hypothetical, and they had no expectation of obtaining these items.

Browsers viewed the same 12 products and were asked to judge which four products would be most useful when traveling, by clicking on four products and dragging them into a box labeled "Travel Items." There was no significant difference in the amount of time spent on the Choosing and Browsing tasks (60.7 s vs. $58.2 \mathrm{~s} ; t(98)<1)$.

We then administered a third (and final) measure of emotions, identical to our baseline measure.

We conducted a pre-test on MTurk $(\mathrm{N}=42,43 \%$ female, mean age: 33 ) to confirm that the Choosing task was more likely to generate feelings of control than the Browsing task. Participants completed both the Choosing and Browsing tasks (which were labeled the Shopping Cart task and the Travel Items task, respectively, for participants). The order of tasks was counterbalanced across participants. We then asked, "In which task did you feel you had more control over the items you selected?" Participants selected one of five options: Definitely the Travel Items task, Probably the Travel Items task, No difference between the Shopping Cart and Travel Items tasks, Probably the Shopping Cart task, and Definitely the Shopping Cart task. Seventy-nine percent of participants reported that they (probably or definitely) felt more control while Choosing, whereas only $2 \%$ reported that they (probably or definitely) felt more control while Browsing $\left(\chi^{2}(1)=50.6, p<.0001\right)$. Thus, while both tasks likely generate, to some extent, a sense of personal control over one's environment, the Choosing task is a more effective way to increase a sense of personal control.

Results

To verify that our manipulation worked as intended, we examined whether the selection of products reflected greater autonomy among Choosers. Free choice among options imbues a sense of control and autonomy by allowing people to implement or reveal their individual preferences. Browsers 
were asked to select the products most appropriate for travel, but only a handful of the products were appropriate for travel. By contrast, Choosers were free to select any product. Choosers' greater ability to control which products they select should be reflected by greater variance in their selections.

Fig. 2 displays the proportion of participants selecting each product by condition. There was significantly greater variance in product selection among Choosers than Browsers $(F(1,22)=$ $4.47, p<.05$, Levene's test). If Browsers could freely choose to the same extent as Choosers, there would be a similar degree of variance in selected products across conditions. The unequal variance in product selections across conditions is consistent with the notion that Choosers experienced more control during the task.

We next tested our central hypothesis that choosing would be more likely than browsing to alleviate residual sadness. Sad and depressed ratings correlated highly $(r(98)>.65, p<.0001$ at each measurement), and were averaged to form a sadness index at each measurement. We created a residual sadness score by subtracting participants' baseline index scores from their final index scores. This commonly-used method controls for broad individual differences in the tendency to experience and express emotions (cf. Kermer, Driver-Linn, Wilson, \& Gilbert, 2006; Oveis et al., 2009; Rogosa \& Willett, 1983; Wilson, Wheatley, Meyers, Gilbert, \& Axsom, 2000). Three outliers, with residual sadness scores more than three standard deviations from the mean, were excluded.

As expected, residual sadness scores were significantly lower among Choosers than Browsers $(M=2.9, S D=8.6$ vs. $M=8.1$, $S D=14.5 ; t(95)=2.13, p<.05)$. In other words, making hypothetical buying choices was more likely to return participants to their baseline level of sadness than was browsing.
Thus, Experiment 1 provides initial support for the hypothesis that making shopping choices helps to alleviate residual sadness. The results of the pre-test and the greater variance in product selections among Choosers suggest that the mechanism underlying this effect is a restoration of personal control.

\section{Experiment 2}

Experiment 2 extends our investigation in three ways. First, all participants made real (consequential) shopping decisions. Second, to isolate the role of restored control in retail therapy, all participants actually obtained their preferred option, but we manipulated the extent to which they had apparent control over the process of obtaining that option. Third, to shed additional light on the process of personal control restoration, we examined whether the benefits of making shopping choices are specific to sadness or generalize to other negative emotions. In particular, we examined whether making shopping choices also helps to alleviate anger. Anger is generally as aversive as sadness, but is associated with a sense that other people (rather than situational forces) cause negative outcomes (Smith \& Ellsworth, 1985). Whereas making shopping choices may help restore a sense of personal control over one's environment, those choices are unlikely to reduce the extent to which other people are viewed as unfairly or unduly influential. Thus, enhancing control over one's environment should have more impact on sadness than on anger.

\section{Method}

One hundred forty-seven undergraduates from a Midwestern university participated for course credit. Six participants who

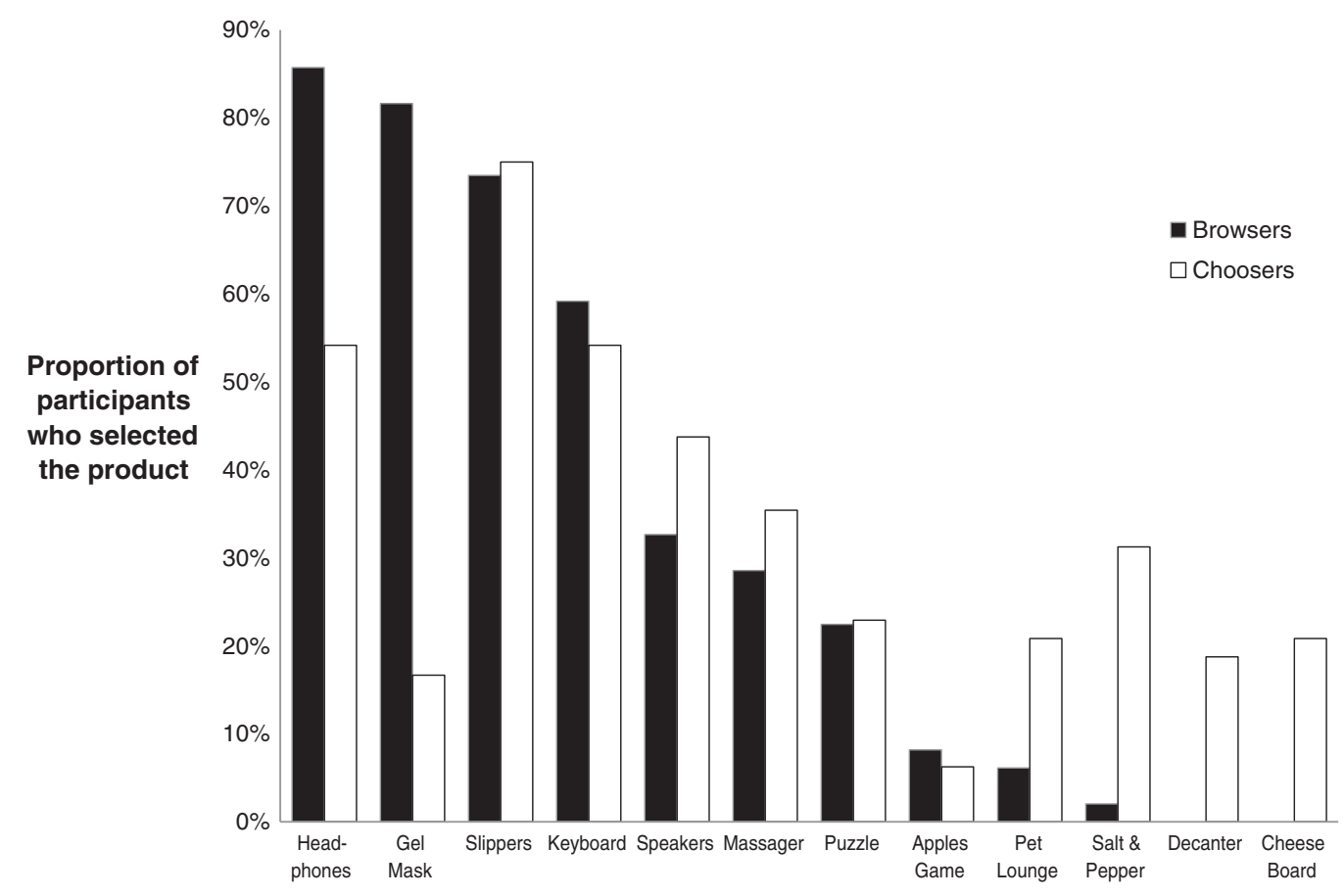

Fig. 2. Proportion of participants selecting each product by condition (Experiment 1). 
failed to follow instructions (e.g., texting during the experiment) were excluded. We initially collected a baseline measure of eight emotions (sad, indifferent, angry, happy, depressed, enraged, amused, neutral) on 0-100 scales.

We then induced either sadness or anger. In the Sadness condition, participants viewed the same clip from The Champ used in Experiment 1. In the Anger condition, participants viewed a 2.5-minute clip from Cry Freedom that portrays young, unarmed protesters being gunned down by opposition forces. This clip reliably induces anger (Rottenberg et al., 2007).

Following the emotion induction, participants were told that they would be given a $\$ 5$ spending budget as part of a real shopping experience. They were told that they could buy one of three products (a set of post-it notes, a set of highlighters, or a set of ball point pens), all offered in the lab for $\$ 5$ (approximately equal to their actual retail prices). They were also told that they could choose to buy none of these products, and trade in their spending budget for $\$ 1$ in real cash. We disincentivized not buying because walking away with the full $\$ 5$ budget would have been an easy choice for most participants (as they did not come to the lab intending to stock up on office supplies). This ensured that there was engagement in the shopping task and that choices were actively considered. Our sadness versus anger induction did not significantly influence the proportion of participants choosing to buy one of the products $(62 \%$ vs. $74 \%$, $\left.\chi^{2}(1)=2.46, p>.10\right)$. We pooled across the buyer versus non-buyer distinction in our analyses, since both actively made a choice.

We also embedded a manipulation of personal agency in the shopping task by adapting a procedure validated by Berman and Small (2012). Specifically, we told participants that, after they made their choice, the computer would randomly draw a number from 1 to 10 . If the randomly generated number was even, they would simply obtain whatever they chose. However, if the randomly generated number was odd, the computer would ignore their choice and randomly make a selection on their behalf. Note that there were four possible choices in our paradigm - buying the post-it notes, buying the highlighters, buying the pens, or trading in the spending budget for $\$ 1$ in real cash. Regardless of participants' own choice, if the randomly generated number was odd, participants believed that the computer could randomly select any one of these four options on their behalf.

In the Personal Control condition, the randomly selected number was even, and participants were told that they would obtain what they chose. In the Situational Control condition, the randomly selected number was odd, and then the computer ostensibly made a random selection on their behalf (in fact, always selecting the option participants had selected for themselves). Thus, at the end of this task and before collecting our final measure of emotions, all participants knew that they would obtain the option they preferred. All that varied across the Personal Control versus Situational Control conditions was the amount of control participants believed they had over the process.

We then administered a second (and final) measure of emotions, identical to our baseline measure. Finally, participants either obtained their selected product or $\$ 1$ in cash.
Results

Sad and depressed ratings correlated highly $(r(139)>.42$, $p<.0001$ at each measurement), and were averaged to form a sadness index at each measurement. Angry and enraged ratings correlated highly $(r(139)>.56, p<.0001$ at each measurement), and were averaged to form an anger index at each measurement. We created residual sadness and anger scores by subtracting participants' baseline index scores from their final index scores.

Fig. 3 displays the focal residual emotion in each condition (i.e., residual sadness in the Sadness conditions and residual anger in the Anger conditions). As predicted, residual sadness scores in the Sadness conditions were significantly higher in the Situational Control condition than in the Personal Control condition $(M=3.73$, $S D=10.78$ vs. $M=-2.28, S D=11.79 ; t(69)=2.24, p<.05)$. However, residual anger scores in the Anger conditions did not differ significantly between the Situational Control and Personal Control conditions $(M=14.75, S D=25.69$ vs. $M=14.17, S D=30.91 ; t(68)=.09, p=.93){ }^{1}$

Experiment 2 suggests that real shopping can help to alleviate residual sadness, unless that shopping experience further reduces personal control over situational forces. By contrast, restoring personal control is as ineffective as further jeopardizing personal control at alleviating residual anger. Anger is naturally associated with a sense that other people are likely to cause negative outcomes, and thus restoring control over ambient environmental forces does not appear to address the key control deficit associated with anger.

\section{Experiment 3}

Experiment 3 extends our investigation by focusing more closely on the underlying mechanism of personal control restoration. Specifically, we examine whether a direct manipulation of control over one's environment (outside of a shopping context) is more likely to influence sadness than anger.

\section{Method}

Three hundred and one undergraduates from a Southern university $(51 \%$ female) participated for course credit. We initially collected a baseline measure of nine emotions (happy, angry, sad, indifferent, enraged, depressed, amused, anxious, and neutral) on $0-100$ scales.

\footnotetext{
${ }^{1}$ It is worth noting that the Situational Control versus Personal Control manipulation did not operate by influencing happiness, despite the fact that residual happiness (final happy rating minus baseline happy rating) was significantly correlated with both residual sadness $(r(139)=-.48, p<.0001)$ and residual anger $(r(139)=-.28, p<.001)$, pooling across conditions. Residual happiness in the Sadness conditions did not differ significantly between the Situational Control and Personal Control conditions $(M=7.02$, $S D=28.22$ vs. $M=4.61, S D=25.49 ; t(69)=.38, p=.71) . \quad$ Likewise, residual happiness in the Anger conditions did not differ significantly between the Situational Control and Personal Control conditions $(M=7.83, S D=33.38$ vs. $M=17.15, S D=29.96 ; t(68)=1.23, p=.22)$.
} 


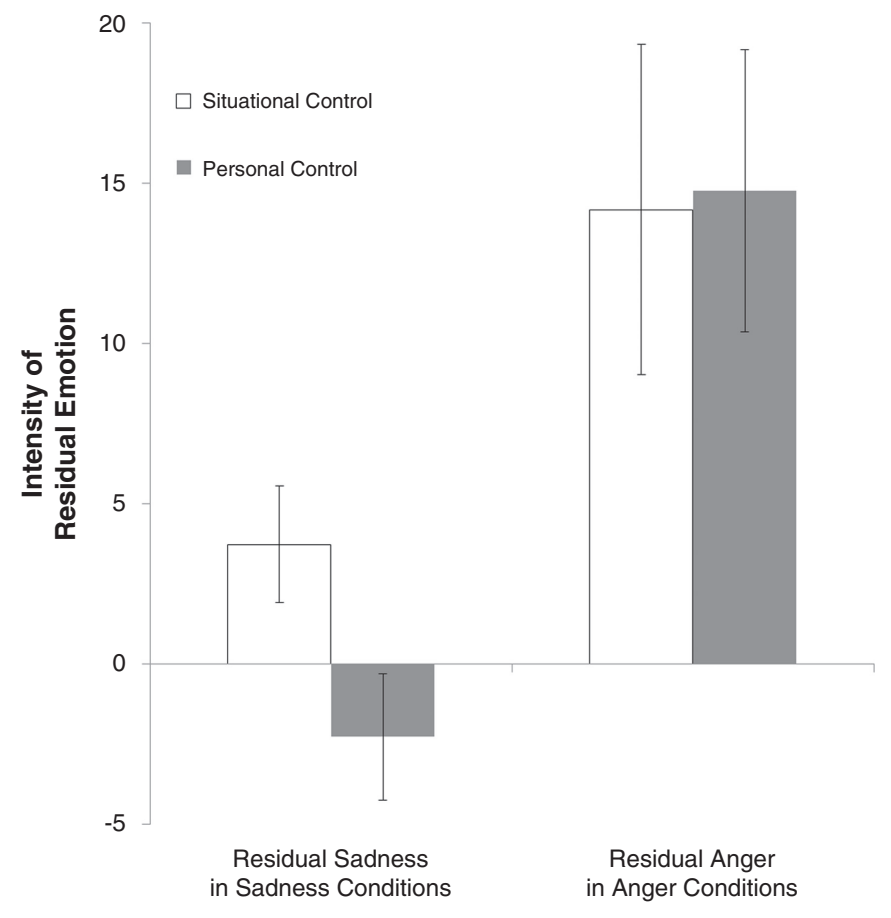

Note: Error bars represent \pm 1 standard error.

Fig. 3. Focal residual emotion by condition (Experiment 2).

We then induced sadness, anger, or neutral emotion. We included a Neutral condition to examine whether our subsequent control manipulation (discussed below) generated any emotional costs or benefits even in the absence of a negative emotion induction. In the Sadness condition, participants viewed the clip from The Champ used in previous experiments. In the Anger condition, participants viewed a four-minute clip from My Bodyguard that portrays a bullying incident. This clip reliably induces anger (Rottenberg et al., 2007). In the Neutral condition, participants viewed a 2.5-minute clip from National Geographic about coral reefs (cf. Lerner et al., 2004).

Following the emotion induction, we asked participants to either recall an instance in which they experienced control over an important situation (Personal Control condition) or experienced no control over an important situation (Situational Control condition). We carefully worded our recall prompts to prevent participants from considering instances in which they had control over other people, or were controlled by other people (see Appendix).

We then administered a second (and final) measure of emotions, identical to our baseline measure.

\section{Results}

Sad and depressed ratings correlated highly $(r(299)>.67$, $p<.0001$ at each measurement), and were averaged to form a sadness index at each measurement. Angry and enraged ratings correlated highly $(r(299)>.73, p<.0001$ at each measurement), and were averaged to form an anger index at each measurement. We created residual sadness and anger scores by subtracting participants' baseline index scores from their final index scores.

Fig. 4 displays the focal residual emotion in the Sadness and Anger conditions. As predicted, residual sadness scores in the Sadness conditions were significantly higher in the Situational Control condition than in the Personal Control condition $(M=$ $12.1, S D=14.8$ vs. $M=2.89, S D=16.3 ; t(99)=2.97, p<.01)$. However, residual anger scores in the Anger conditions did not differ significantly between the Situational Control and Personal Control conditions $(M=4.6, S D=14.8$ vs. $M=4.7, S D=17.7$; $t(97)=.03, p=.97)$.

In the Neutral conditions, both residual sadness and residual anger were slightly higher in the Situational Control condition than in the Personal Control condition, though neither difference was statistically significant (residual sadness: $M=3.7, S D=15.5$ vs. $M=-0.3, S D=7.3 ; t(99)=1.74, \quad p=.085 ;$ residual anger: $M=3.6, S D=11.0$ vs. $M=0.2, S D=6.1 ; t(99)=1.97$, $p=.052$ ). Residual scores for all the other individual emotions measured (happy, indifferent, amused, anxious, neutral) also did not differ significantly across the Situational Control and Personal Control conditions (all $p \mathrm{~s}>.05$ ). Thus, the Neutral condition offers marginal evidence suggesting that personal control can help to mitigate mild levels of naturally occurring sadness and anger. However, Fig. 4 suggests that when experiences of sadness and anger are more focal and acute, personal control uniquely helps to alleviate sadness.

Thus, consistent with our theoretical framework (and Experiment 2), Experiment 3 suggests that the acute experience of sadness (which is naturally associated with a sense that situational forces control outcomes) is smaller when personal

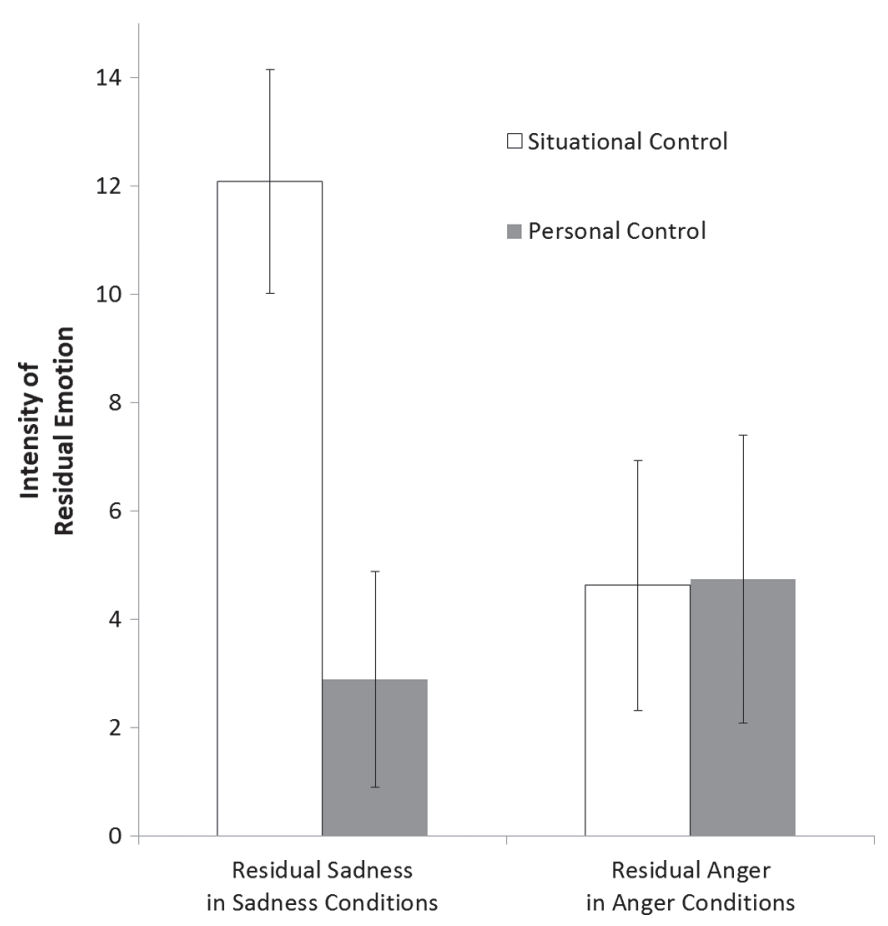

Note: Error bars represent \pm 1 standard error.

Fig. 4. Focal residual emotion by condition (Experiment 3). 
control over one's environment is restored than when it is further jeopardized. By contrast, the acute experience of anger (which is naturally associated with a sense that other people cause negative outcomes) is unaffected by differences in control over one's environment. To the extent that making shopping choices enhances feelings of personal control over one's environment, these results suggest that shopping is likely to alleviate sadness but not necessarily anger.

\section{General discussion}

Previous research suggests that distress can increase willingness to spend (e.g., Atalay \& Meloy, 2011; Lerner et al., 2004), but the question of whether "retail therapy" actually helps to reduce distress has only been addressed in correlational designs, utilizing surveys and interviews of people who chose to shop when feeling bad. We addressed this gap by experimentally examining whether making shopping choices could help to reduce residual sadness.

Three experiments provided support for the notion that making shopping choices helps to restore a sense of personal control over one's environment, and thus helps to alleviate residual sadness. We observed these benefits regardless of whether the shopping was hypothetical or real. We also documented support for the underlying mechanism of personal control restoration. We found that the effects of manipulating personal control over one's environment did not generalize to anger. Anger is associated with a sense that other people are likely to cause negative outcomes, and changes in personal control over situational forces cannot necessarily reduce the extent to which other people are viewed as unfairly or unduly influential.

Our work contributes to research on emotion and decisionmaking. Most work in this area has focused on how specific emotions influence decision-making and consumption (e.g., Cryder et al., 2008; Garg \& Lerner, 2013; Garg, Wansink, \& Inman, 2007; Lerner et al., 2004). By contrast, our paper joins a growing stream of research examining how decision-making influences the experience of specific emotions (Berman \& Small, 2012; Gal \& Liu, 2011).

Our work also contributes to appraisal theories of emotion. Prior work had demonstrated that the cognitive appraisals that accompany an emotion can be deactivated by addressing the source of emotion (e.g., the cognitive effects of anger are extinguished when the perpetrator that caused the anger is punished; Goldberg, Lerner, \& Tetlock, 1999). Our work suggests that counteracting a particular cognitive appraisal (here, restoring personal control after it has been lost) may help to extinguish the emotion that elicited the appraisal, consistent with the "recursive" nature of emotions and their associated appraisals (Han et al., 2007).

\section{Limitations and future directions}

An ideal test of the impact of restored personal control on the experience of sadness and anger would require inductions that initially produced similarly intense experiences of sadness and anger (before the focal control manipulation). Otherwise, differences in initial emotional intensity could potentially explain differences in responsiveness to the focal control manipulation. Unfortunately, pooling across the Personal and Situational Control conditions in Experiment 2, residual anger in the Anger conditions was significantly greater than residual sadness in the Sadness conditions ( 14.45 vs. $0.68, p<.01)$. By contrast, residual anger in the Anger conditions was slightly lower than residual sadness in the Sadness conditions in Experiment 3 (4.67 vs. 7.53, $p=.21$ ). Despite these differences (within and across experiments), we always found that residual sadness was sensitive to the Personal versus Situational control manipulations, but residual anger never was. Thus, our results do not appear to be an artifact of intensity differences across induced emotions. (An intensity account would suggest that only the most intense or least intense emotion would be influenced by our control manipulations.)

Future research on retail therapy could examine shopping aspects other than choice that might address the key symptom (sadness) but not its cause (loss of personal control). While we carefully controlled for many features associated with shopping so that we could isolate restoration of control as a key feature of retail therapy, we believe that residual sadness may also be reduced in ways that do not directly address the control deficit. For example, social interaction may increase positive emotions and perhaps mitigate sadness (O'Guinn \& Faber, 1989). The distraction provided by shopping is another possibility. Neither of these shopping aspects replace the lost control intrinsic to sadness, but both may impact a consumer's overall emotional state.

Future research could also further explore the foundational link between control and sadness. We found that restoring personal control following exposure to sad stimuli helped to reduce residual sadness. Future work could examine whether imbuing people with high personal control helps immunize them from the effects of sad stimuli encountered later.

\section{Conclusion}

Retail therapy is often considered wasteful and ineffective. For example, when we asked 100 adults (52\% female, mean age: 35 ) for the first word that came to mind when hearing "retail therapy," they were more than twice as likely to provide a clear negative response (e.g., nonsense, debt) than to provide a clear positive response (e.g., fun, enjoyment) $\left(19 \%\right.$ vs. $8 \% ; \chi^{2}(1)=5.18$, $p<.05$; other responses were neutral, such as shopping). But no prior research had experimentally examined whether and why shopping when sad can actually help to reduce residual sadness. Our work suggests that making shopping choices can help to restore a sense of personal control over one's environment and reduce residual sadness. Whether the increased control afforded by shopping results in a loss of control later (due to increased debt), and thus counteracts the temporary benefits of retail therapy, remains an important open question.

\section{Authors' note}

We thank the Editor, the Associate Editor, three anonymous reviewers, Simona Botti, Cynthia Cryder, and Gabriele Paolacci for valuable feedback. 


\section{Appendix. Control inductions used in Experiment 3}

\section{Situational control}

Please recall a particular incident in which you did not have any control over a situation important to you. By control, we mean a circumstance in which you could not control your environment in a way that allowed you to achieve something you wanted. For instance, this could be a time when you failed to exert the control necessary to overcome an obstacle, or when your actions could not change an important situation to meet your needs. Note that this does not involve lack of control-or lack of power-over other people, just lack of control over your environment. Please describe this situation in which you did not have any control-what happened, how you felt, etc.

\section{Personal control}

Please recall a particular incident in which you had complete control over a situation important to you. By control, we mean a circumstance in which you controlled your environment in a way that allowed you to achieve something you wanted. For instance, this could be a time when you succeeded in exerting control to overcome an obstacle, or when your actions effectively changed an important situation to meet your needs. Note that this does not involve control - or power-over other people, just control over your environment. Please describe this situation in which you had complete, effective control-what happened, how you felt, etc.

\section{References}

Atalay, A. S., \& Meloy, M. G. (2011). Retail therapy: A strategic effort to improve mood. Psychology and Marketing, 28(6), 638-659.

Berman, J. Z., \& Small, D. A. (2012). Self-Interest without selfishness: The hedonic benefit of imposed self-interest. Psychological Science, 23(10), 1193-1199.

Cryder, C. E., Lerner, J. S., Gross, J. J., \& Dahl, R. E. (2008). Misery is not miserly: Sad and self-focused individuals spend more. Psychological Science, 19(6), 525-530.

Faber, R. J., \& Christenson, G. A. (1996). In the mood to buy: Differences in the mood states experienced by compulsive buyers and other consumers. Psychology and Marketing, 13(8), 803-819.

Gal, D., \& Liu, W. (2011). Grapes of wrath: The angry effects of self-control. Journal of Consumer Research, 38(3), 445-458.

Gardner, M. P., \& Rook, D. W. (1988). Effects of impulse purchases on consumers' affective states. In M. J. Houston (Ed.), Advances in Consumer Research. (pp. 127-130) Provo, UT: Association for Consumer Research.

Garg, N., \& Lerner, J. S. (2013). Sadness and consumption. Journal of Consumer Psychology, 23(1), 106-113.
Garg, N., Wansink, B., \& Inman, J. J. (2007). The influence of incidental affect on consumers' food intake. Journal of Marketing, 71(1), 194-206.

Goldberg, J. H., Lerner, J. S., \& Tetlock, P. E. (1999). Rage and reason: The psychology of the intuitive prosecutor. European Journal of Social Psychology, 29, 781-795.

Han, S., Lerner, J. S., \& Keltner, D. (2007). Feelings and consumer decision making: The appraisal-tendency framework. Journal of Consumer Psychology, 17(3), 158-168.

Inesi, M. E., Botti, S., Dubois, D., Rucker, D. D., \& Galinsky, A. D. (2011). Power and choice: Their dynamic interplay in quenching the thirst for personal control. Psychological Science, 22(8), 1042-1048.

Kasser, T., \& Sheldon, K. M. (2000). Of wealth and death: Materialism, mortality salience, and consumption behavior. Psychological Science, 11(4), 348-351.

Kermer, D. A., Driver-Linn, E., Wilson, T. D., \& Gilbert, D. T. (2006). Loss aversion is an affective forecasting error. Psychological Science, 17(8), 649-653.

Kim, S., \& Rucker, D. D. (2012). Bracing for the psychological storm: Proactive versus reactive compensatory consumption. Journal of Consumer Research, 39(4), 815-830.

Langer, E. J. (1975). The illusion of control. Journal of Personality and Social Psychology, 32(2), 311-328.

Lerner, J. S., \& Keltner, D. (2001). Fear, anger, and risk. Journal of Personality and Social Psychology, 81(1), 146-159.

Lerner, J. S., Small, D. A., \& Loewenstein, G. (2004). Heart strings and purse strings: Carryover effects of emotions on economic decisions. Psychological Science, 15(5), 337-341.

Mazar, N., \& Zhong, C. -B. (2010). Do green products make us better people? Psychological Science, 21(4), 494-498.

O’Guinn, T. C., \& Faber, R. J. (1989). Compulsive buying: A phenomenological exploration. Journal of Consumer Research, 16, 147-157.

Oveis, C., Cohen, A. B., Gruber, J., Shiota, M. N., Haidt, J., \& Keltner, D. (2009). Resting respiratory sinus arrhythmia is associated with tonic positive emotionality. Emotion, 9(2), 265-270.

Paolacci, G., Chandler, J., \& Ipeirotis, P. G. (2010). Running experiments on Amazon Mechanical Turk. Judgment and Decision Making, 5(5), 411-419.

Raghunathan, R., Pham, M. T., \& Corfman, K. P. (2006). Informational properties of anxiety and sadness, and displaced coping. Journal of Consumer Research, 32(4), 596-601.

Rogosa, D. R., \& Willett, J. B. (1983). Demonstrating the reliability of the difference score in the measurement of change. Journal of Educational Management, 20(4), 335-343.

Rottenberg, J., Ray, R. D., \& Gross, J. J. (2007). Emotion elicitation using films. In J. A. Coan, \& J. J. B. Allen (Eds.), The handbook of emotion elicitation and assessment (pp. 9-28). New York: Oxford University Press.

Smith, C. A., \& Ellsworth, P. C. (1985). Patterns of cognitive appraisal in emotion. Journal of Personality and Social Psychology, 48(4), 813-838.

Spencer, S. J., Zanna, M. P., \& Fong, G. T. (2005). Establishing a causal chain: Why experiments are often more effective than mediational analyses in examining psychological processes. Journal of Personality and Social Psychology, 89(6), 845-851.

Tuttle, B. (2010, July 19). Seeking 'retail therapy' when what you need is real therapy. Time Magazine, July 19, 2010 (Retrieved from http://moneyland. time.com/2010/07/19/too-much-retail-therapy-and-youll-need-real-therapy)

Wilson, T. D., Wheatley, T., Meyers, J. M., Gilbert, D. T., \& Axsom, D. (2000). Focalism: A source of durability bias in affective forecasting. Journal of Personality and Social Psychology, 78(5), 821-836. 